\title{
Effect of Crystallinity on Thermal Diffusivities of Mould Fluxes for the Continuous Casting of Steels
}

\author{
Miyuki HAYASHI, Riad ABDUL ABAS and Seshadri SEETHARAMAN \\ Department of Materials Science and Engineering, Royal Institute of Technology, Brinellvägen 23, SE-100 44 Stockholm, \\ Sweden.
}

(Received on October 30, 2003; accepted in final form on December 15, 2003)

\begin{abstract}
The thermal diffusivities of mould flux having the glassy and crystalline states were measured as a function of temperature by the laser flash method to obtain the relationship between the thermal diffusivity and the degree of crystallization. The thermal diffusivities of the liquid mould flux were also measured to compare the data with those of the solid samples. The thermal diffusivity increases roughly linearly with an increase in the degree of crystallization. The thermal diffusivities of glassy and liquid samples having the ratios of $\mathrm{NBO} / \mathrm{T}=1.48,1.65$ and 2.11 exhibit roughly the same values of $4.6 \times 10^{-7} \mathrm{~m}^{2} \mathrm{~s}^{-1}$ and $4.0 \times$ $10^{-7} \mathrm{~m}^{2} \mathrm{~s}^{-1}$, respectively. It is considered that because the silicate network is largely broken down, there is not a significant change of the structure for these samples.
\end{abstract}

KEY WORDS: thermal diffusivity; mould flux; laser flash method; degree of crystallization; silicate network.

\section{Introduction}

In the continuous casting of steels, one of the factors affecting the surface quality of the product is the heat transfer process occurring in the mould, which is dominantly influenced by the characteristics of the mould powder infiltrated into the mould/strand gap. The mould powder forms a slag film between mould and solidified steel shell, which frequently consists of glassy, crystalline and liquid layers. The heat transfer from the steel shell to the mould is composed of the conduction and radiation heat flows through various slag layers, and the thermal resistance at the mould/slag interface. Therefore, it is necessary to have fundamental data of thermal conductivities and optical properties of mould powders having glassy, crystalline and liquid states to estimate the heat flow. However, despite of the importance, there are very few data of thermophysical properties of mould powders. ${ }^{1)}$

Thermal conductivities/diffusivities of liquid slags have been measured by different researchers. ${ }^{2-11)}$ They have reported the similar values of thermal conductivities although their temperature dependences are in disagreement with each other, that is, thermal conductivities measured by the hot-wire method have shown large negative temperature dependences, however, those measured by the laser flash method show the negligible or moderate positive or negative temperature dependences. With respect to the thermal conductivity/diffusivity of mould powders in the glassy and crystalline states, there are fewer previous reports available. Shibata et al. ${ }^{12)}$ have measured thermal diffusivities of mould powders in the glassy and crystalline states and have reported that the thermal diffusivities of the crystalline samples show 1.4 and 1.2 times higher than those of the glassy samples at room temperature and $800 \mathrm{~K}$, respective- ly. Taylor and Mills ${ }^{13)}$ have also reported that the thermal diffusivities of the crystalline samples are higher than those of the glassy samples. However, since the thermal conductivity/diffusivity of the solid slag is considered to be dependent on the crystallinity, the property should be measured as a function of the degree of crystallization as well as the temperature. In the present study, the thermal diffusivities of the mould powders having the glassy and crystalline states were measured as a function of temperature by the laser flash method to obtain the relationship between the thermal diffusivity and the degree of crystallization. The thermal diffusivities of the liquid mould powders were also measured to compare with those of the solid samples.

\section{Experimental}

\subsection{Sample Preparation}

The chemical compositions of the four proprietary mould powders are given in Table 1 . The mould powders were decarburised by heating in air for $48 \mathrm{~h}$ at $1073 \mathrm{~K}$. The decarburised powders were placed in platinum crucibles and melted in air for $0.25 \mathrm{~h}$ at $1623 \mathrm{~K}$ for powder $\mathrm{A}$, and at $1573 \mathrm{~K}$ for powders B-D. Glassy samples were prepared by pouring the melts onto a stainless steel plate kept at $723 \mathrm{~K}$. Subsequently, the samples were annealed in air for $1 \mathrm{~h}$ at $773 \mathrm{~K}$ and cooled down by the furnace cooling rate to eliminate the residual stress. Discs having about $12 \mathrm{~mm}$ in diameter and 1.5 to $2.5 \mathrm{~mm}$ in thickness were machined from the glassy samples. Crystalline samples were made by annealing the glassy samples having the disc shape at 1073 and $1173 \mathrm{~K}$ for $1-120 \mathrm{~h}$. Since the surfaces of the annealed samples became very rough because of the crystallization, the surfaces were polished to obtain the parallelism between both faces. 
Table 1. Chemical compositions of the proprietary mould powders (mass $\%$ ).

\begin{tabular}{|c|c|c|c|c|}
\hline & $\mathrm{A}$ & $\mathrm{B}$ & $\mathrm{C}$ & $\mathrm{D}$ \\
\hline $\mathrm{SiO}_{2}$ & 25.5 & 32.7 & 34.2 & 28.8 \\
\hline $\mathrm{CaO}$ & 22.7 & 28.8 & 29.4 & 36.5 \\
\hline $\mathrm{MgO}$ & 0.97 & 1.77 & 1.01 & 1.3 \\
\hline $\mathrm{Al}_{2} \mathrm{O}_{3}$ & 12 & 4.7 & 3.92 & 6.5 \\
\hline $\mathrm{TiO}_{2}$ & 0.46 & 0.11 & 0.1 & 0.3 \\
\hline $\mathrm{Fe}_{2} \mathrm{O}_{3}$ & 2.86 & 1.24 & 1.09 & 0.8 \\
\hline $\mathrm{MnO}$ & 0.04 & $<0.10$ & 0.05 & 3.3 \\
\hline $\mathrm{Na}_{2} \mathrm{O}$ & 2.62 & 11.3 & 12.8 & 7.2 \\
\hline $\mathrm{K}_{2} \mathrm{O}$ & 1.43 & 0.31 & 0.37 & 0.1 \\
\hline $\mathrm{F}$ & 4.42 & 9.4 & 7.95 & 5.9 \\
\hline
\end{tabular}

\subsection{Thermal Diffusivity Measurement}

Thermal diffusivities of solid mould powders were measured over a temperature range between room temperature and $773 \mathrm{~K}$ for glassy samples, and between room temperature and $773-1023 \mathrm{~K}$ for crystalline samples in a flow of argon by the laser flash apparatus (Model TC-7000H/MELT Ulvac-Riko). In the laser flash technique, the top surface of a pellet is irradiated with a laser which provides an instantaneous energy pulse. The laser energy is absorbed on the top surface of a sample to convert it to the heat energy, and the heat energy travels through the sample. Immediately after the laser pulse, the temperature of the rear surface of the sample is monitored by collecting radiation using a photovoltaic infrared detector. The signal from the detector is amplified and sent to a computer for analysis. The thermal diffusivity, $\alpha$, is obtained from Eq. (1) ${ }^{14)}$

$$
\alpha=\frac{0.1388 L^{2}}{t_{1 / 2}}
$$

where $L$ is the thickness of the sample and $t_{1 / 2}$ is the time required for the temperature of the rear surface to reach half of its maximum temperature. Because the glassy samples of powders $\mathrm{A}-\mathrm{C}$ were transparent, both sides of all samples were coated by a thin carbon layer using carbon spray (Graphite spray, Svenska Tanso AB, Sweden) to convert the laser pulse into the heat energy on the surface efficiently and to increase the sensitivity of the infrared detector. ${ }^{12)}$ Measurements were started at room and were carried out during the heating cycle at first and then during the cooling cycle.

With respect to the thermal diffusivity measurement of liquid mould powders, the three-layered cell arrangement ${ }^{7}$ ) was employed. The three layers are composed of the liquid sample having the form of a thin film, sandwiched between two platinum crucibles. The laser pulse is exposed on the top surface of the upper crucible and the temperature rise
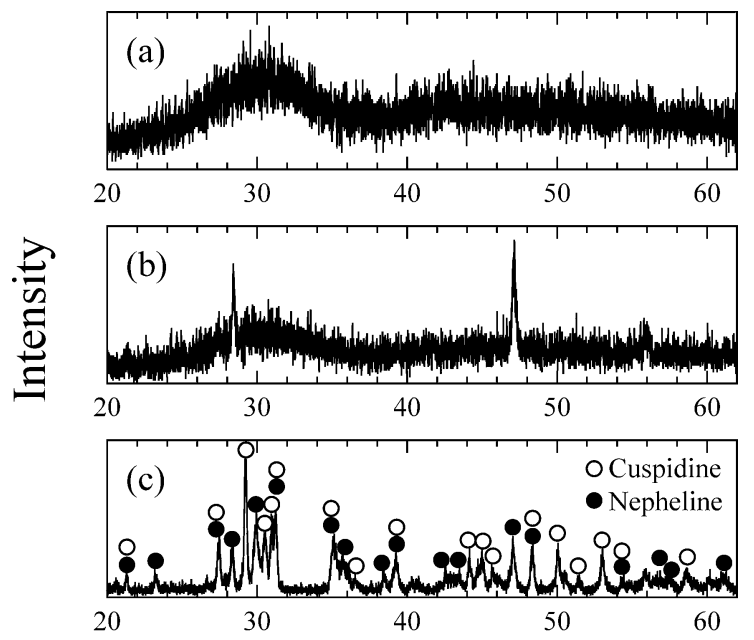

$2 \theta / \operatorname{deg}$.

Fig. 1. X-ray diffraction profiles of the glassy sample (a) and the samples annealed at $1073 \mathrm{~K}$ for $1 \mathrm{~h}(\mathrm{~b})$ and $15 \mathrm{~h}$ (c) for powder A.

on the rear surface of the lower crucible is monitored as a function of time for a sample having two different thicknesses. The thickness is changed by changing the position of the lower crucible by accurately known distance. The details of the principle and the apparatus adopted here have been reported elsewhere. ${ }^{10,11)}$ Measurements were carried out over a temperature range between 1523 and $1773 \mathrm{~K}$ during the cooling cycle. In order to obtain the reliable measurement values, the thermal diffusivity measurement was repeated six to eight times at each temperature. For powder $\mathrm{C}$, two runs were conducted.

\subsection{Crystallinity Measurement}

X-ray diffraction studies were carried out for the glassy and crystalline samples to determine the phase and the degree of crystallization. As described in Sec. 3, X-ray diffraction profiles of crystalline samples have shown that cuspidine $\left(\mathrm{Ca}_{4} \mathrm{Si}_{2} \mathrm{O}_{7} \mathrm{~F}_{2}\right)$ has appeared for all powders and nepheline $\left(\mathrm{Na}_{3} \mathrm{KAl}_{4} \mathrm{Si}_{4} \mathrm{O}_{16}, \mathrm{NaAlSiO}_{4}\right)$ has been also observed for powders $\mathrm{A}$ and $\mathrm{B}$. Because the largest peak of $\mathrm{Mn}_{2} \mathrm{O}_{3}$ at $2 \theta=32.951^{\circ}$. does not overlap with any crystalline peaks and the largest peak of cuspidine at $2 \theta=29.150^{\circ}$. does not overlap with any peaks of $\mathrm{Mn}_{2} \mathrm{O}_{3}$, the degree of crystallization was defined as the ratio of the largest peak intensity of cuspidine to that of $\mathrm{Mn}_{2} \mathrm{O}_{3}$ observed for the X-ray diffraction profile of the well mixed powders of $1.0 \mathrm{~g}$ of samples and $0.15 \mathrm{~g}$ of $\mathrm{Mn}_{2} \mathrm{O}_{3}{ }^{15}$ )

\section{Results}

X-ray diffraction profiles of all glassy samples detect no traces of crystalline phases, indicating that all glassy samples are amorphous from the viewpoint of X-ray diffraction. Figure 1 shows the X-ray diffraction profiles of the glassy sample (a) and the samples annealed at $1073 \mathrm{~K}$ for $1 \mathrm{~h} \mathrm{(b)} \mathrm{and} 15 \mathrm{~h} \mathrm{(c)} \mathrm{for} \mathrm{powder} \mathrm{A.} \mathrm{It} \mathrm{can} \mathrm{be} \mathrm{seen} \mathrm{from} \mathrm{Fig.}$ 1(b) that for the sample annealed at $1073 \mathrm{~K}$ for $1 \mathrm{~h}$, two sharp peaks appear together with the hallow pattern due to the amorphous phase. Two sharp peaks may be attributed to 


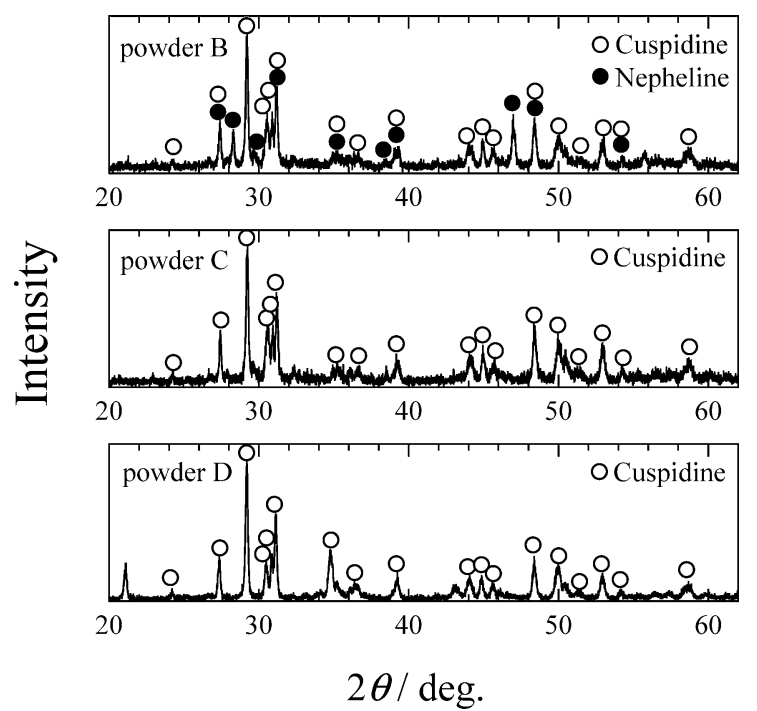

Fig. 2. X-ray diffraction profiles of the samples annealed at $1073 \mathrm{~K}$ for $1 \mathrm{~h}$ for powders $\mathrm{B}-\mathrm{D}$.

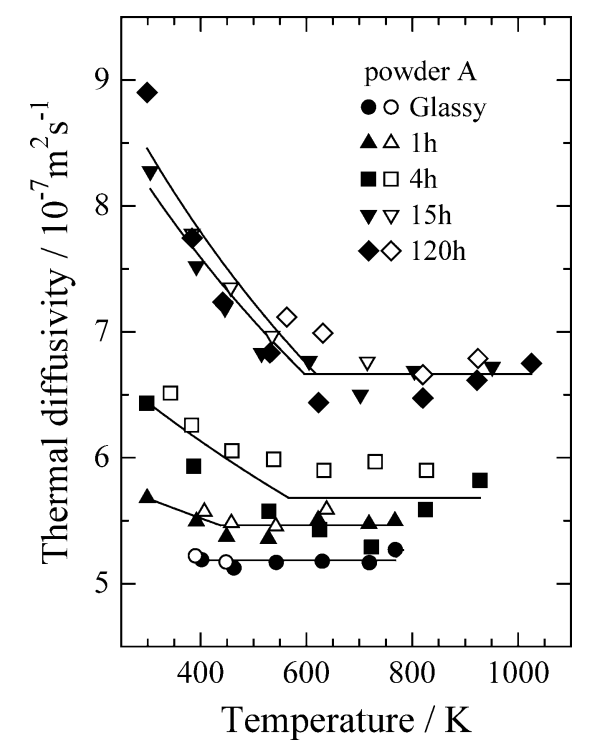

Fig. 3. Temperature dependences of the thermal diffusivities of the glassy sample and the samples annealed at $1073 \mathrm{~K}$ for $1-120 \mathrm{~h}$ for powder A. Closed symbols are data recorded during the heating cycles and open symbols during the cooling cycles.

nepheline $\left(\mathrm{Na}_{3} \mathrm{KAl}_{4} \mathrm{Si}_{4} \mathrm{O}_{16}, \mathrm{NaAlSiO}_{4}\right)$. On the other hand, Fig. 1(c) shows that the hallow pattern disappears and only sharp peaks are observed for the sample annealed at $1073 \mathrm{~K}$ for $15 \mathrm{~h}$, indicating that the sample has been mostly crystallized. Marking has been made at the angles where the diffraction peaks attributed to cuspidine $\left(\mathrm{Ca}_{4} \mathrm{Si}_{2} \mathrm{O}_{7} \mathrm{~F}_{2}\right)$ and nepheline $\left(\mathrm{Na}_{3} \mathrm{KAl}_{4} \mathrm{Si}_{4} \mathrm{O}_{16}, \mathrm{NaAlSiO}_{4}\right)$ should be observed.

Figure 2 shows the X-ray diffraction profiles of the samples annealed at $1073 \mathrm{~K}$ for $1 \mathrm{~h}$ for powders B-D. Marking has been made at the angles where the diffraction peaks attributed to cuspidine and nepheline should be observed for powder $\mathrm{B}$, and at the angles where the peaks due to cuspidine should be observed for powders $C$ and $D$.

Figure 3 shows the temperature dependences of the thermal diffusivities of the glassy sample and the samples an-

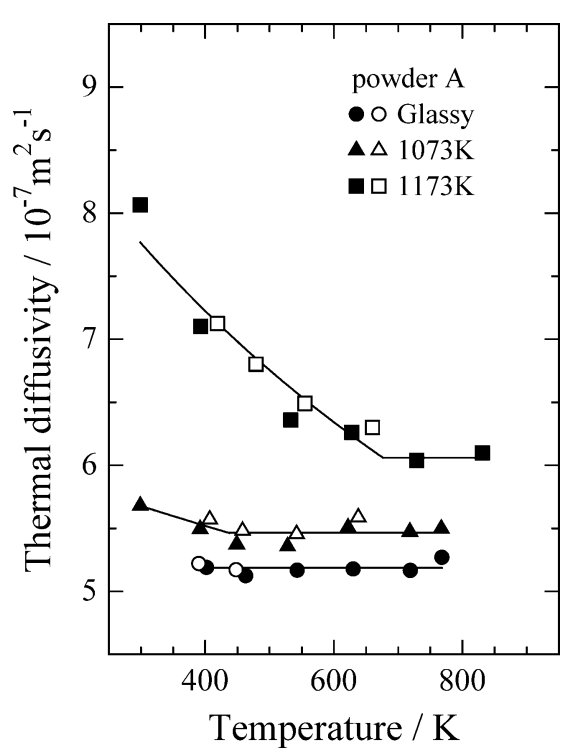

Fig. 4. Temperature dependencies of the thermal diffusivities of the glassy sample and the samples annealed for $1 \mathrm{~h}$ at 1073 and $1173 \mathrm{~K}$ for powder A. Closed symbol are data recorded during the heating cycles and open symbols during the cooling cycles.

nealed at $1073 \mathrm{~K}$ for $1-120 \mathrm{~h}$ for powder A. Closed symbols are data recorded during the heating cycles and open symbols during the cooling cycles. As for the glassy sample, the thermal diffusivities were measured at $773 \mathrm{~K}$ for the samples having two different thicknesses, 2.653 and 2.012 $\mathrm{mm}$, which are found to be $5.270 \times 10^{-7} \mathrm{~m}^{2} \mathrm{~s}^{-1}$ and $5.266 \times 10^{-7} \mathrm{~m}^{2} \mathrm{~s}^{-1}$, respectively. The agreement of two thermal diffusivity values demonstrates that the radiation effect on the thermal diffusivity at $773 \mathrm{~K}$ is negligible for the glassy sample. If the radiation contribution on the thermal diffusivity is appreciable, the measured thermal diffusivity value should be larger as the specimen is thicker for optically thin samples. It can be seen from Fig. 3 that the thermal diffusivity of the glassy sample is constant within the measurement temperatures. However, the thermal diffusivities of the crystalline samples decrease with increasing temperature at lower temperatures and are roughly constant at higher temperatures. These temperature dependences are in agreement with those reported by Shibata et al. ${ }^{12)}$ It can be also seen that the sample annealed for longer time exhibits larger thermal diffusivity. Figure 4 shows the temperature dependences of the thermal diffusivities of the glassy sample and the samples annealed for $1 \mathrm{~h}$ at 1073 and $1173 \mathrm{~K}$ for powder $\mathrm{A}$. The sample annealed for higher temperature shows larger thermal diffusivity. Figures 5, 6 and 7 show the temperature dependencies of the thermal diffusivities of the glassy and crystalline samples for powders B, $\mathrm{C}$ and $\mathrm{D}$, respectively. In contrast to powder $\mathrm{A}$, the thermal diffusivities of these glassy samples decrease with an increase in temperature at lower temperatures and are constant at higher temperatures. The temperature dependencies of the thermal diffusivities of all glassy samples are shown in Fig. 8. It can be seen from Figs. 3, 4, 5 and 6 that for some crystalline samples, thermal diffusivities obtained during the cooling cycle are larger than those obtained during the heating cycle. This is probably because the samples became more crystallized during the thermal diffusivity 


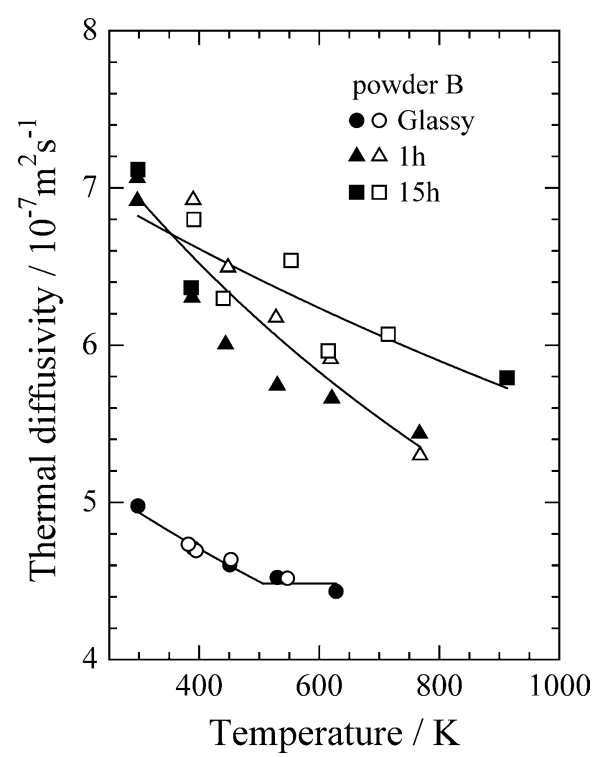

Fig. 5. Temperature dependencies of the thermal diffusivities of the glassy and crystalline samples for powders B. Closed symbol are data recorded during the heating cycles and open symbols during the cooling cycles.

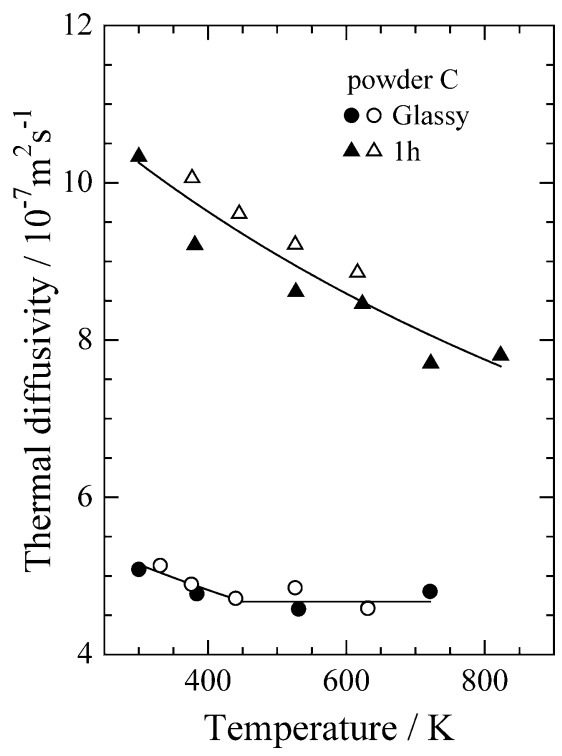

Fig. 6. Temperature dependencies of the thermal diffusivities of the glassy and crystalline samples for powders C. Closed symbol are data recorded during the heating cycles and open symbols during the cooling cycles.

measurement at high temperatures.

Figure 9 shows the relationship between the thermal diffusivity at room temperature and the ratio of the largest peak intensity of the X-ray diffraction of cuspidine to that of $\mathrm{Mn}_{2} \mathrm{O}_{3}$ for all samples. The thermal diffusivity roughly linearly increases with an increase in the peak intensity ratio, however, more data scatter is noticed as the peak intensity ratio is higher.

Figure 10 shows the temperature dependences of the apparent thermal diffusivities of liquid samples for powders B-D. In the case of powder A, the thermal diffusivity measurement was not successful because when the position of the lower crucible was changed the platinum crucible was deformed because of the very high viscosity of the sample. The error bars represent the standard deviation of the ex-

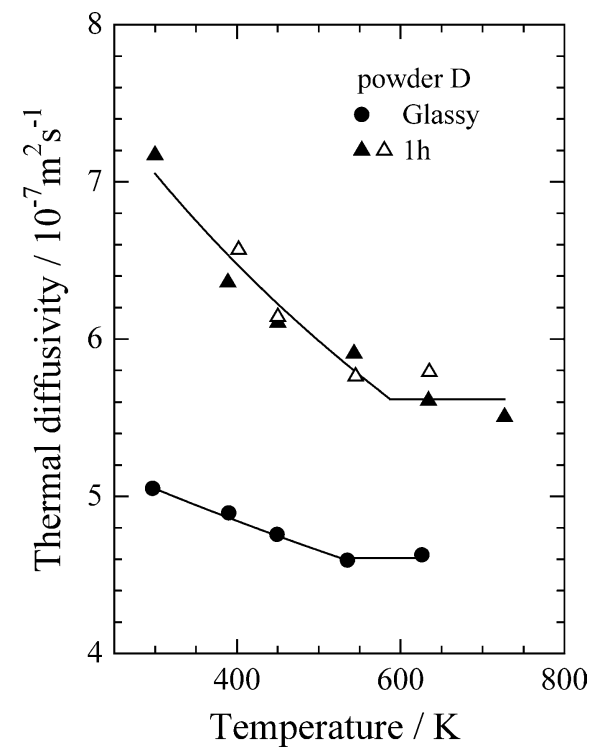

Fig. 7. Temperature dependencies of the thermal diffusivities of the glassy and crystalline samples for powders D. Closed symbol are data recorded during the heating cycles and open symbols during the cooling cycles.

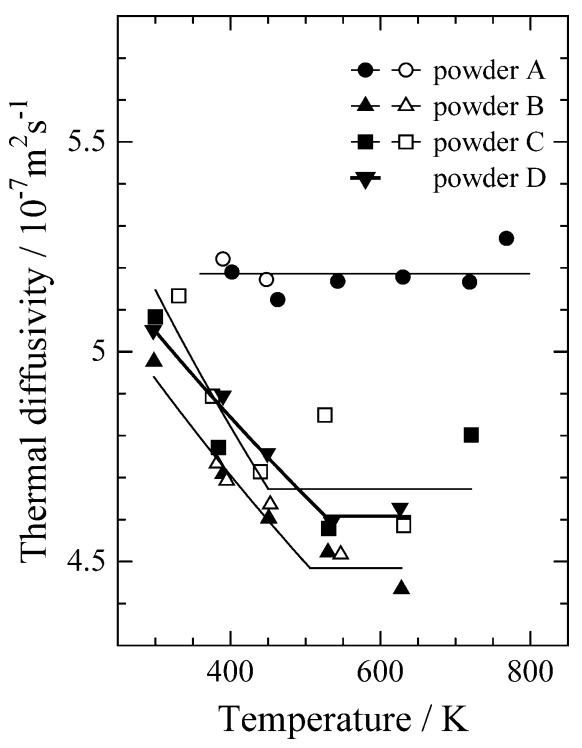

Fig. 8. Temperature dependencies of the thermal diffusivities of all glassy samples.

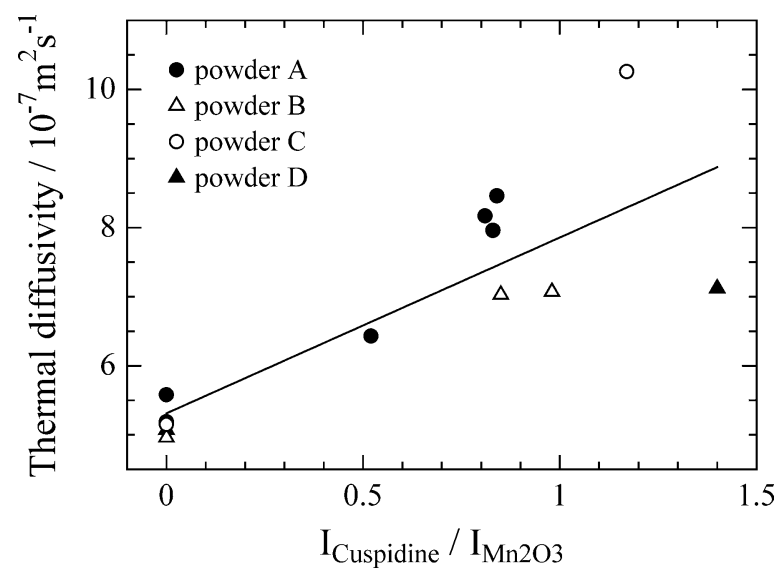

Fig. 9. Relationship between the thermal diffusivity at room temperature and the ratio of the first peak intensity of the X-ray diffraction of cuspidine to that of $\mathrm{Mn}_{2} \mathrm{O}_{3}$ for all samples. 


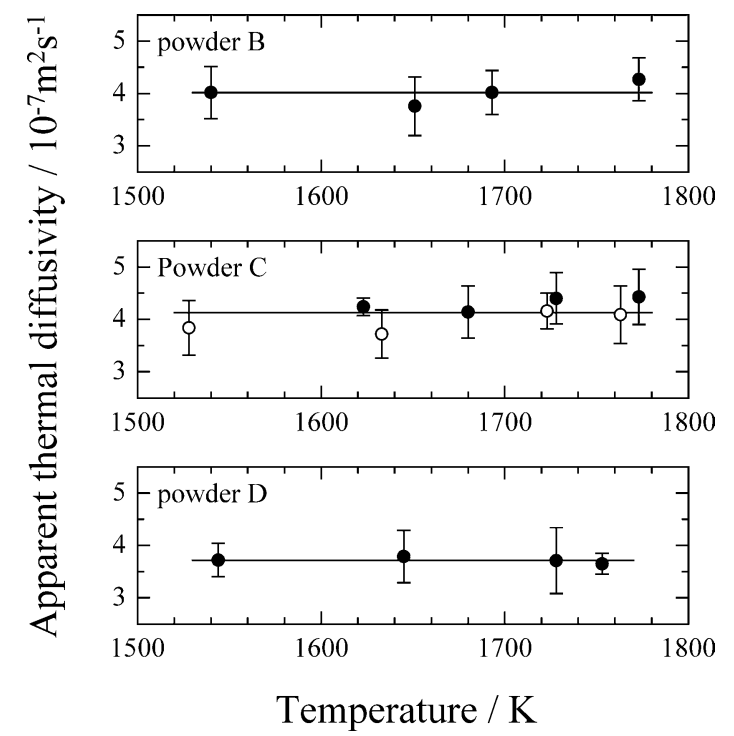

Fig. 10. Temperature dependencies of the apparent thermal diffusivities of liquid samples of powders B-D.

perimental values. It is found that the temperature dependences of the apparent thermal diffusivities are negligible for all powders. The thermal diffusivity of powder $\mathrm{D}$ is slightly lower than those of powders B and C.

\section{Discussion}

\subsection{Temperature Dependences of the Thermal Diffu- sivities of the Crystalline Samples}

Generally, thermal conductivity is determined by lattice vibration (phonon conduction) in insulators. Debye ${ }^{16)}$ proposed that the thermal conductivity of insulators $\lambda$ is expressed as the following equation by analogy with kinetic theory of gases,

$$
\lambda=\frac{1}{3} C_{\mathrm{v}} v l
$$

where $C_{\mathrm{v}}$ is the heat capacity at constant volume in $\mathrm{J} / \mathrm{Km}^{3}$, $v$ the velocity of sound and $l$ the phonon mean free path. From the definition of the thermal diffusivity $\alpha$,

$$
\lambda=\alpha \rho C_{\mathrm{p}}
$$

where $\rho$ and $C_{\mathrm{p}}$ are the density and the heat capacity, respectively. $C_{\mathrm{v}} \approx \rho C_{\mathrm{p}}$ is applied because the work by thermal expansion is negligible for the solid state. Then, Eqs. (2) and (3) yield,

$$
\alpha=\frac{1}{3} v l
$$

If it is assumed that the value of $v$ is constant irrespective of temperature, the thermal diffusivity is proportional to the phonon mean free path. The phonon mean free path is determined principally by two mechanisms, geometrical scattering, i.e., the collisions of a phonon with the crystal boundary, lattice imperfections and so on, and phononphonon interaction, i.e., so-called umklapp processes. The reciprocal of the effective mean free path $1 / l$ is found by adding the reciprocal of the mean free path for geometrical

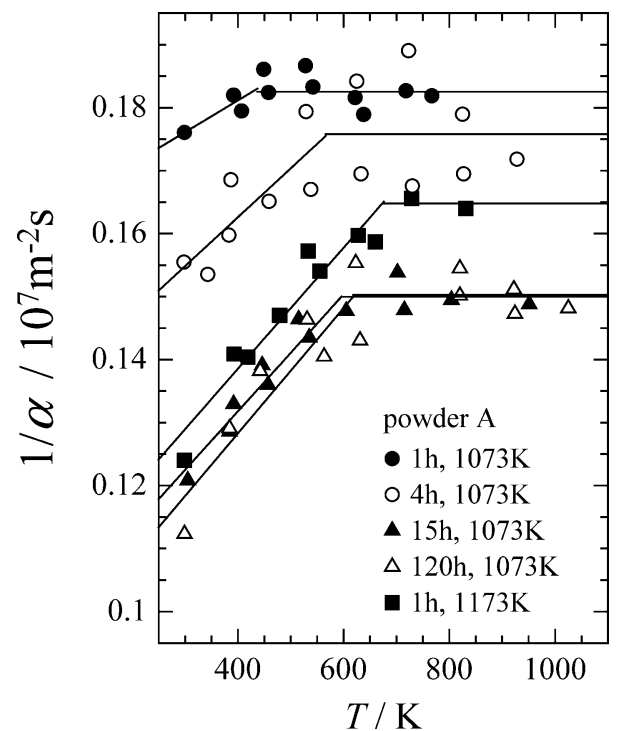

Fig. 11. Reciprocal of the thermal diffusivity as a function of temperature for crystalline samples of powder A.

scattering $l_{\text {geo }}$ and that for phonon-phonon interaction $l_{\mathrm{p}-\mathrm{p}}$, as follows;

$$
\frac{1}{l}=\frac{1}{l_{\mathrm{geo}}}+\frac{1}{l_{\mathrm{p}-\mathrm{p}}}
$$

Generally above room temperatures, the geometrical scattering is independent of temperature. On the other hand, the mean free path determined by phonon-phonon interaction is inversely proportional to temperature above the Debye temperature. ${ }^{17)}$ Therefore, Eq. (5) is rewritten by

$$
\frac{1}{l}=a+b T
$$

where $T$ is the absolute temperature and $a$ and $b$ constants. Figure 11 shows the reciprocal of the thermal diffusivity, which is considered to be proportional to the reciprocal of the phonon mean free path, as a function of temperature for crystalline samples of powder A. It is found that the reciprocal of thermal diffusivity, i.e., the reciprocal of the phonon mean free path obeys Eq. (6) below 400-600 K. The solid lines in Figs. 3-8 have been drawn based on Eq. (6) for the temperature regions where the thermal diffusivity shows the negative temperature dependence. The geometrical scattering may be caused by grain boundaries of crystalline phases and boundaries between glassy and crystalline phases for the crystalline samples. However, the authors have no idea with respect to the meaning of the geometrical scattering for the glassy samples. It can be also seen from Figs. 3-7 that at high temperatures the thermal diffusivities become constant for all samples except for the crystalline samples of powders B and C. It has been known that if the temperature is raised to a sufficiently high level, the phonon mean free path decreases to a fixed value by the random network structure, and is expected to be independent of temperature. ${ }^{17)}$ Here, the phonon mean free path fixed by the random network structure is evaluated by Eq. (4). Nagata et ll $^{18)}$ have reported that the velocity of sound 
is about $5 \mathrm{~km} / \mathrm{s}$ around $700 \mathrm{~K}$ for the $\mathrm{Na}_{2} \mathrm{O}-\mathrm{SiO}_{2}$ glasses. If the value is used as $v$, the value of $l$ can be calculated as $0.27-0.4 \mathrm{~nm}$ from Eq. (4), which is $2-3$ times larger than $\mathrm{Si}-\mathrm{O}$ bond distance $(0.16 \mathrm{~nm}){ }^{19)}$

\subsection{Thermal Diffusivities of Glassy and Liquid Sam- ples}

It can be seen from Fig. 8 that while the thermal diffusivity of the glassy sample of powder A is constant irrespective of temperature, the thermal diffusivities of the glassy samples of powders B-D decrease with an increase in temperature at lower temperatures and are constant at higher temperatures. It is also found that the constant value of the thermal diffusivity of powders B-D is lower than that of powder A. As described above, thermal diffusivity of a glassy sample becomes constant independent of temperature when the phonon mean free path is limited to a fixed value by the random network structure. The randomness of the network is considered to be estimated by the ratio of non-bridging oxygen (NBO) atoms/( $\mathrm{Si}+\mathrm{Al}$ atoms) denoted by $\mathrm{NBO} / \mathrm{T}^{20)} \mathrm{Mills}^{21)}$ has found a relationship that the thermal conductivity of silicates at the melting point decreases proportionally with an increase in the $\mathrm{NBO} / \mathrm{T}$ ratio. The $\mathrm{NBO} / \mathrm{T}$ ratios of powders $\mathrm{A}, \mathrm{B}, \mathrm{C}$ and $\mathrm{D}$ can be calculated to be $0.92,1.48,1.65$ and 2.11 , respectively, in the manner proposed by Mills ${ }^{22}$ by assuming that fluorine predominantly bonds to calcium rather than other cations ${ }^{23)}$ and that $\mathrm{CaF}_{2}$ does not contribute to the breakage of the silicate network. ${ }^{24)}$ Consequently, it is found that the NBO/T ratio of powder $\mathrm{A}$ is the smallest and the thermal diffusivity of the same is the largest among four powders. This result is in agreement with the aforementioned relationship proposed by Mills. ${ }^{21)}$ However, the theramal diffusivities of the glassy samples of powders B-D show roughly the same values of $4.6 \times 10^{-7} \mathrm{~m}^{2} \mathrm{~s}^{-1}$ despite of the different $\mathrm{NBO} / \mathrm{T}$ ratios. As shown in Fig. 10, the apparent thermal diffusivities of the liquid samples for powders B-D also show the similar values of $4.0 \times 10^{-7} \mathrm{~m}^{2} \mathrm{~s}^{-1}$. It is considered that because the silicate network is dominantly broken down for powders $\mathrm{B}$, $\mathrm{C}$ and $\mathrm{D}$, the phonon mean free path determined by the randomness of structure doesn't show significant difference among three powders, therefore, the thermal diffusivity is independent of the ratio of $\mathrm{NBO} / \mathrm{T}$. This trend has been also reported in our previous data. ${ }^{10)}$

\subsection{Relationship between the Thermal Diffusivity and the Degree of Crystallization}

It can be seen from Fig. 9 that the thermal diffusivity increases roughly linearly with an increase in the ratio of the largest peak intensity of cuspidine to that of $\mathrm{Mn}_{2} \mathrm{O}_{3}$, however, more data scatter is noticed as the peak intensity ratio is higher. Powders A and B are considered to contain nepheline as well as cuspidine although the degree of crystallization defined in this study only consider cuspidine for crystalline phases. However, this imperfection for the definition of the degree of crystallization does not explain the scatter of the data at higher degree of crystallization. This may imply that the difference in morphology (size and distribution) of crystalline and glassy phases also affects the thermal diffusivity values.

\section{Conclusions}

The thermal diffusivities of four mould powders having the glassy and crystalline states were measured over a temperature range between room temperature and $773 \mathrm{~K}$ and between room temperature and 773-1 $023 \mathrm{~K}$, respectively, in a flow of argon by the laser flash method. The relationship between the thermal diffusivity at room temperature and the degree of crystallization was obtained, where the degree of crystallization was defined as the ratio of the largest peak intensity of cuspidine to that of $\mathrm{Mn}_{2} \mathrm{O}_{3}$ observed for the X-ray diffraction profile of the well mixed powders of $1.0 \mathrm{~g}$ of samples and $0.15 \mathrm{~g}$ of $\mathrm{Mn}_{2} \mathrm{O}_{3}$. The thermal diffusivities of the liquid mould powders were also measured over a temperature range between 1523 and $1773 \mathrm{~K}$ to compare the data with those of the solid samples. The obtained results are summarized as follows.

(1) The thermal diffusivities of the mould powders having the glassy and crystalline states decrease with an increase in temperature at lower temperatures and are constant at higher temperatures except for one glassy sample.

(2) The thermal diffusivity of a glassy sample with the lowest ratio of $\mathrm{NBO} / \mathrm{T}(0.92)$ is larger than those for powders having the higher NBO/T ratios $(1.48,1.65$ and 2.11$)$ because the mean free path is limited by the random network structure and the glassy sample having less random network exhibits higher thermal diffusivity.

(3) The thermal diffusivity of glassy and liquid samples having the ratios of $\mathrm{NBO} / \mathrm{T}=1.48,1.65$ and 2.11 are roughly the same values of $4.6 \times 10^{-7} \mathrm{~m}^{2} \mathrm{~s}^{-1}$ and $4.0 \times$ $10^{-7} \mathrm{~m}^{2} \mathrm{~s}^{-1}$, respectively. It is considered that because the silicate network is largely broken down, there is not a significant change of structure for these powders.

(4) The thermal diffusivity roughly linearly increases with an increase in the degree of crystallization, however, more data scatter at higher degree of crystallization. This may imply that the difference in morphology (size and distribution) of crystalline and glassy phases also affects the thermal diffusivity values.

\section{Acknowledgement}

The present research was made possible by a grant from Jernkontoret (the Swedish Steel Producers' Association).

\section{REFERENCES}

1) M. Susa, K. C. Mills, M. J. Richardson, R. Taylor and D. Stewart: Ironmaking Steelmaking, 21 (1994), 279.

2) T. Sakuraya, T. Emi, H. Ohta and Y. Waseda: J. Jpn. Inst. Met., 46 (1982), 1131

3) K. Nagata, M. Susa and K. S. Goto: Tetsu-to-Hagané, 69 (1983), 51.

4) H. Ohta, Y. Waseda and Y. Shiraishi: Proc. of 2nd Int. Symp. on Metallurgical Slags and Fluxes, The Metallurgical Society of AIME, Colorado, (1984), 863

5) M. Kishimoto, M. Maeda, K. Mori and Y. Kawai: Proc. of 2nd Int. Symp. on Metallurgical Slags and Fluxes, The Metallurgical Society of AIME, Colorado, (1984), 891.

6) K. Nagata and K. S. Goto: Proc. of 2nd Int. Symp. on Metallurgical Slags and Fluxes, The Metallurgical Society of AIME, Colorado, (1984), 875.

7) Y. Waseda, M. Masuda, K. Watanabe, H. Shibata, H. Ohta and K. Nakajima: High Temp. Mater. Process., 13 (1994), 267.

8) M. Hayashi, H. Ishii, M. Susa, H. Fukuyama and K. Nagata: Phys Chem. Glasses, 42 (2001), 6

9) M. Susa, S. Kubota, M. Hayashi and K. C. Mills: Ironmaking 
ISIJ International, Vol. 44 (2004), No. 4

Steelmaking, 28 (2001), 390

10) R. Eriksson, M. Hayashi and S. Seetharaman: Int. J. Thermophys., 24 (2003), 785.

11) R. Eriksson and S. Seetharaman: "Thermal Diffusivity Measurements of some Synthetic $\mathrm{CaO}-\mathrm{Al}_{2} \mathrm{O}_{3}-\mathrm{SiO}_{2}$ Slags" Metall. Mater. Trans., in press.

12) H. Shibata, T. Emi, Y. Waseda, K. Kondo, H. Ohta and K. Nakajima: Tetsu-to-Hagané, 82 (1996), 504.

13) R. Taylor and K. C. Mills: Ironmaking Steelmaking, 15 (1988), 187.

14) W. J. Parker, R. J. Jenkins, C. P. Butler and G. L. Abbott: J. Appl. Phys., 32 (1961), 1679

15) M. Hanao, M. Kawamoto, M. Hara, T. Murakami, H. Kikuchi and K. Hanazaki: Tetsu-to-Hagané, 88 (2002), 23.

16) P. Debye: Vorträge über die kinetische Theorie der Materie und Elektrizität, Gottinger Wolfskehlvortrage. B. G. Teubner, Leipzig and Berlin, (1914), 46.
17) W. D. Kingery, H. K. Bowen and D. R. Uhlmann: Introduction to Ceramics, John Wiley \& Sons, Inc., New York, (1976), 612.

18) K. Nagata, K. Ohira, H. Yamada and K. S. Goto: Metall. Trans. B, 18B (1987), 549.

19) Y. Waseda and J. M. Toguri: The Structure and Properties of Oxide Melts, World Scientific, Singapore, (1998), 23.

$20)$ B. O. Mysen, D. Virgo and C. M. Scarfe: Am. Mineralogist, 65 (1980), 690.

21) K. C. Mills, Proc. 3rd Int. Conf. on Molten Slags and Fluxes, Glasgow, The Institute of Metals, London, (1989), 229.

22) K. C. Mills: Slag Atlas, 2nd. ed., ed. by Verein Deutscher Eisenhüttenleute, Verlag Stahleisen GmbH, (1995), 6.

23) M. Hayashi, T. Watanabe, K. Nagata and S. Hayashi: Tokyo Institute of Technology, unpublished research, (2002).

24) M. Hayashi, N. Nabeshima, H. Fukuyama and K. Nagata: ISIJ Int., 42 (2002), 352 